OPEN ACCESS

Edited by:

Nada Andelic,

University of Oslo, Norway

Reviewed by:

Solrun Sigurdardottir.

Sunnaas Sykehus, Norway

Torgeir Hellstrøm,

Oslo University Hospital, Norway

${ }^{*}$ Correspondence:

Suzanne Polinder

s.polinder@erasmusmc.nl

Specialty section:

This article was submitted to

Neurotrauma,

a section of the journal

Frontiers in Neurology

Received: 27 September 2018 Accepted: 05 December 2018

Published: 19 December 2018

Citation:

Polinder S, Cnossen MC, Real RGL,

Covic A, Gorbunova A,

Voormolen DC, Master CL,

Haagsma JA, Diaz-Arrastia $R$ and

von Steinbuechel N (2018) A

Multidimensional Approach to Post-concussion Symptoms in Mild

Traumatic Brain Injury.

Front. Neurol. 9:1113.

doi: 10.3389/fneur.2018.01113

\section{A Multidimensional Approach to Post-concussion Symptoms in Mild Traumatic Brain Injury}

\author{
Suzanne Polinder ${ }^{1 *}$, Maryse C. Cnossen ${ }^{1}$, Ruben G. L. Real ${ }^{2}$, Amra Covic ${ }^{2}$, \\ Anastasia Gorbunova ${ }^{2}$, Daphne C. Voormolen ${ }^{1}$, Christina L. Master ${ }^{3}$, \\ Juanita A. Haagsma ${ }^{1,4}$, Ramon Diaz-Arrastia ${ }^{5}$ and Nicole von Steinbuechel ${ }^{2}$ \\ ${ }^{1}$ Department of Public Health, Erasmus MC, University Medical Center Rotterdam, Rotterdam, Netherlands, ${ }^{2}$ Institute of \\ Medical Psychology and Medical Sociology, Georg-August-University, Göttingen, Germany, ${ }^{3}$ Department of Pediatrics, \\ University of Pennsylvania Perelman School of Medicine, Philadelphia, PA, United States, ${ }^{4}$ Department of Emergency \\ Medicine, Erasmus Medical Center Rotterdam, Rotterdam, Netherlands, ${ }^{5}$ Department of Neurology, University of \\ Pennsylvania Perelman School of Medicine, Philadelphia, PA, United States
}

Mild traumatic brain injury (mTBI) presents a substantial burden to patients, families, and health care systems. Whereas, recovery can be expected in the majority of patients, a subset continues to report persisting somatic, cognitive, emotional, and/or behavioral problems, generally referred to as post-concussion syndrome (PCS). However, this term has been the subject of debate since the mechanisms underlying post-concussion symptoms and the role of pre- and post-injury-related factors are still poorly understood. We review current evidence and controversies concerning the use of the terms post-concussion symptoms vs. syndrome, its diagnosis, etiology, prevalence, assessment, and treatment in both adults and children. Prevalence rates of post-concussion symptoms vary between 11 and $82 \%$, depending on diagnostic criteria, population and timing of assessment. Post-concussion symptoms are dependent on complex interactions between somatic, psychological, and social factors. Progress in understanding has been hampered by inconsistent classification and variable assessment procedures. There are substantial limitations in research to date, resulting in gaps in our understanding, leading to uncertainty regarding epidemiology, etiology, prognosis, and treatment. Future directions including the identification of potential mechanisms, new imaging techniques, comprehensive, multidisciplinary assessment and treatment options are discussed. Treatment of post-concussion symptoms is highly variable, and primarily directed at symptom relief, rather than at modifying the underlying pathology. Longitudinal studies applying standardized assessment strategies, diagnoses, and evidence-based interventions are required in adult and pediatric mTBI populations to optimize recovery and reduce the substantial socio-economic burden of post-concussion symptoms.

Keywords: mild traumatic brain injury, post-concussion symptoms, outcome, diagnosis, etiology, prevalence, treatment 


\section{INTRODUCTION}

Mild traumatic brain injuries (mTBI) are among the most common neurologic conditions, representing a substantial burden in adults and children (1-3). A subset of mTBI patients suffers from acute post-concussion symptoms that may manifest as somatic symptoms (e.g., nausea, dizziness, headache, blurred vision, auditory disturbance, and fatigue), cognitive complaints (memory and executive function), emotional, and/or behavioral problems (e.g., disinhibition and emotional lability) (4-6).

In $10-25 \%$ of mTBI patients, post-concussion symptoms persist over time (7-10), which is often referred to as postconcussion syndrome (PCS). PCS is usually diagnosed according to the International Classification of Diseases (ICD)-10 (5), or following Diagnostic and Statistical Manual of Mental Disorders (DSM)-IV criteria (6). However, over the last 15 years the concept of PCS as a reliably identifiable, unique syndrome has been questioned $(11,12)$. Therefore, we will use the term postconcussion symptoms to describe symptoms following mTBI and will refer to persistent post-concussion symptoms when these persist for at least 3 months after TBI.

This focused review (based on a systematic literature search until March 1st 2018, see Appendix A) summarizes current knowledge on epidemiology, controversies, etiology, assessment and treatment of post-concussion symptoms in adults and children. Understanding the various factors leading to post-concussion symptoms, and the complex interactions between temporal onset, biological, psychological and social factors, as well as the relative influence of injury-related and non-injury related factors, may contribute toward a better understanding, diagnosis and classification of post-concussion symptoms. Figure 1 shows current topics in research on postconcussion symptoms. In addition, an insight into the wide range of assessment methods and possible treatments may provide guidance for both clinicians (e.g., physician, psychologist, neuropsychologist, neurosurgeon, nurse, physical therapist, and occupational therapist), social worker and policy-makers.

\section{MATERIALS AND METHODS}

\section{Search Strategy and Selection Criteria}

We searched EMBASE and MEDLINE from Jan 1th, 2010 to March 1st 2018, where landmark papers with earlier dates were also integrated. We included papers published in peerreviewed English language journals, identifying observational, experimental, and intervention studies and reviews in civilian mTBI patients with short- and long-term (3-36 m) postconcussion symptoms or syndrome. See Appendix A for the EMBASE search strategy. Additional papers were identified by screening reference lists and citation indices and from authors' own files.After removal of duplicates, articles were excluded on the basis of title and abstract by two reviewers (MC and DV).

To warrant a minimum level of quality, papers were selected for current review if they were either (systematic) reviews or prospective cohort studies that included $\geq 100$ patients. Exceptions were imaging studies, where lower numbers of patients were allowed and studies about treatment, where we prioritized (randomized) controlled trials. If these studies were not available, we used either retrospective or case-control studies, studies with lower number of patients or papers published before 2010. In cases where included papers did not meet our quality threshold [review, prospective cohort $\geq 100$ patients or randomized controlled trials (RCT)], this was explicitly mentioned.

\section{DEFINITIONS AND EPIDEMIOLOGY}

\section{Mild Traumatic Brain Injury (mTBI)}

The American Congress of Rehabilitation Medicine (ACRM) (4) defines mTBI as an "acute brain injury resulting from mechanical energy to the head from external physical forces," with any of the following symptoms: loss of consciousness (LOC) not exceeding $30 \mathrm{~min}$, post-traumatic amnesia (PTA) of no more than $24 \mathrm{~h}$, a score of no $<13$ on the Glasgow Coma Scale (GCS) after 30 min post injury (or upon presentation) (14), and an (unspecified) period of confusion (feeling dazed, disoriented, and confused), or other transient neurologic abnormalities such as focal signs or seizures.

Most mTBI patients do not show trauma-related abnormalities on computed tomography (CT) scans. However, the literature on mTBI frequently distinguishes between complicated and uncomplicated mTBI and the term complicated $m T B I$ is often used to refer to e.g., $5-10 \%$ of emergency department (ED) patients (15) who show abnormalities, such as subarachnoid hemorrhage, intracranial contusions, or small extra-axial hematomas. The prevalence of pediatric mTBI based on emergency department visits are likely underestimated in childhood as studies have demonstrated that most children initially seek care with their primary care doctor for these mild injuries (16). In children, findings on CT are even more rare (17) and multiple effective clinical prediction rules have been developed to reduce unnecessary CT use in children (18). Special consideration should be given for children $<2$ years of age with regard to decision-making about the use of CT scans in the setting of head trauma.

\section{Diagnosis of Post-concussion Syndrome}

PCS is usually defined according to DSM-IV or ICD-10 criteria, which both focus on symptom presentation (19). These manuals agree on the prerequisite history of brain trauma for the diagnosis of post-concussional disorder [DSM-IV (6)] or PCS [ICD-10 (5)]. Differences between diagnostic systems are presented in Table 1. An important difference is that DSM-IV requires immediate symptom onset and persistence for at least 3 months whereas ICD-10 does not. In addition, DSM-IV requires objective evidence of memory or attention deficits (criterion B), but ICD-10 explicitly precludes such evidence (criterion C-3). The variability in terminology and associated criteria of the DSM-IV and ICD-10 hampers accurate identification and diagnosis of patients with PCS (13). Different classification methods may result in overestimation or underestimation of symptoms, particularly when relying on subjective endorsement of symptoms by patients. This was shown in a cross-sectional 


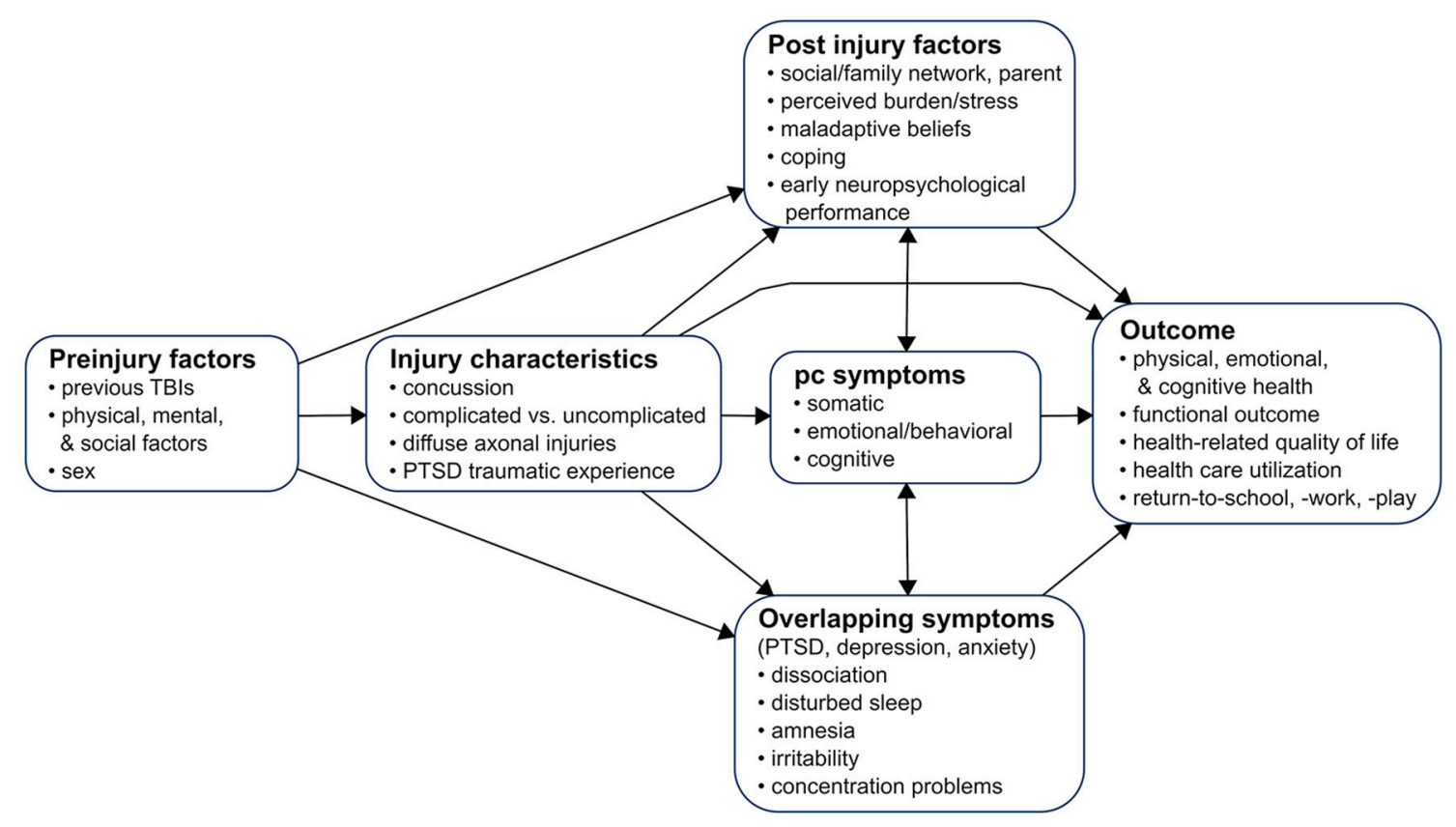

FIGURE 1 | A model for the study of post-concussion symptoms after mTBI. Permission has been obtained to model our figure based on Yeates (13), @ The International Neuropsychological Society 2010, published by Cambridge University Press.

study in which 61 patients were referred to a concussion clinic following mTBI (20).

Post-concussional disorder was not included in the last DSM5 edition (21). Instead, DSM-5 contains "mild neurocognitive disorder due to TBI," a neurocognitive disorder, which strongly suggests-but does not formally require-performance-based, quantifiable evidence of acquired cognitive deficits after mTBI (Table 1). Importantly, DSM-5 denotes the status of the most frequently reported post-concussion symptoms to the level of "associated features." Finally, DSM-5 emphasizes a broad range of differential diagnoses, especially when symptom severity "appears to be inconsistent with the severity of the TBI" (22).

\section{Prevalence of Post-concussion Symptoms}

Prevalence of post-concussion symptoms varies and depends on pre-injury factors $(10,23)$, patient population (24), assessment (24), and analytic strategies, diagnostic criteria (24, 25), and classification methods (26). Overall, single symptoms (e.g., fatigue, headache, and cognitive symptoms) are very common (27) (Figure 2), whereas multiple concurrent symptoms are less frequent (24).

Neuropsychological testing consistently shows minor cognitive deficits within the first 2 weeks after injury, with some exploratory evidence suggesting deficits lasting up to 6 months (28). It has been suggested that self-reported somatic symptoms (headaches, dizziness) are more prevalent immediately after the injury (1-2 weeks) (29), whereas cognitive and emotional symptoms resolve more slowly and may still be above baseline levels long-term post-injury $(30,31)$. However, these crosssectional analyses did not track the evolution of symptoms in single patient groups. Therefore, evidence supporting a differential trajectory between self-reported somatic and cognitive/emotional subacute symptoms is limited.

ICD-10 prevalence rates of PCS at 3 months post-injury vary between 6\% (32), 22\% (33), and 64\% (25). DSM-IV diagnostic criteria appear to be stricter than ICD-10 criteria leading to lower estimates (34): a cohort study of patients after mTBI found a prevalence of PCS at 3 months of $64 \%$ based on ICD-10 criteria, but only a prevalence of $11 \%$ when using DSM-IV (25).

Few pediatric studies report on the prevalence of postconcussion symptoms according to ICD-10 or DSM-IV diagnostic criteria; 1-month prevalence for children recruited from ED based on ICD-10 reach 52\% (35) and 3-month prevalence based on DSM-IV constitutes $29.3 \%$ (36). Some studies define symptomatic children as having an increase in at least one symptom and arrive at estimates between 24.5 and $52.5 \%$ at 1 month post injury $(35,37), 11-39 \%$ after 3 months, and $2.3 \%$ at 12 months (35), which makes comparison of symptom development trends between children and adults challenging. An additional complication in capturing prevalence rates in children is that younger children may not be able to describe their symptoms reliably. Therefore, such prevalence estimates should be treated with caution.

\section{CONTROVERSIES}

Post-concussion symptoms are highly controversial and a major topic of debate among clinicians, methodologists, and health outcome experts. One problem is that post-concussion symptoms do not always cluster in a consistent and predictable manner (12, 
TABLE 1 | Comparison of three definitions of post-concussion symptoms.

\begin{tabular}{llll}
\hline & ICD-10 & DSM-IV & DSM-5 \\
\hline Headache & $\sqrt{ }$ & $\sqrt{ }$ & - \\
Dizziness & $\sqrt{ }$ & $\sqrt{ }$ & - \\
Fatigue & $\sqrt{ }$ & $\sqrt{ }$ & - \\
Noise intolerance & $\sqrt{ }$ & $\sqrt{ }$ & - \\
Irritability/lability/anxiety/ & $\sqrt{ }$ & $\sqrt{ }$ & - \\
depression & & & \\
Sleep problems & $\sqrt{ }$ & $\sqrt{ }$ & - \\
Concentration problems & $\sqrt{ }$ A & $\sqrt{ }{ }^{\mathrm{B}}$ & $\sqrt{ }^{\mathrm{B}}$ \\
Memory deficit & $\sqrt{ }{ }^{\mathrm{A}}$ & $\sqrt{ }{ }^{\mathrm{B}}$ & $\sqrt{ }^{\mathrm{B}}$ \\
Intolerance of alcohol & $\sqrt{ }$ & - & - \\
Preoccupation with & $\sqrt{ }$ & - & - \\
symptoms & & & - \\
Personality change & - & $\sqrt{ }$ & - \\
Apathy & - & $\sqrt{ }$ & $\sqrt{ }^{\mathrm{B}}$ \\
Perceptual-motor & - & - & $\sqrt{ }^{\mathrm{B}}$ \\
Social cognition & - & - & \\
\hline
\end{tabular}

Table shows symptoms presented in the International Classification of Diseases (ICD)-10 definition of PCS (diagnosis code F07.02), the Diagnostic and Statistical Manual of Mental Disorders (DSM)-IV definition of postconcussional disorder and the DSM-V definition of neurocognitive disorder.

A Subjective report.

BObjective test.

19). Therefore, it is controversial whether they truly represent a specific, cohesive, and predictable syndrome (i.e., PCS) $(12,19)$. In addition, although the term post-concussion symptoms might suggest otherwise, these symptoms are not specific to TBI but are also frequently reported in non-brain injured trauma patients (10), including patients with whiplash injuries (38) and in healthy adults and children $(35,39,40)$.

The literature on mTBI frequently uses the term "symptom" to refer to all changes experienced after a concussion. However, when focusing solely on the patient's self-report, the use of the term "complaint" might be more appropriate.

Similarly, the etiology of post-concussion symptoms is also debatable. Although the biopsychosocial model is often applied to explain the onset and persistence of post-concussion symptoms (41), post-concussion symptoms have also been associated with malingering, exaggeration, misattribution, and recall bias, thereby prompting concern regarding the clinical reality of post-concussion symptoms.

\section{Acute and Persistent Post-concussion Symptoms}

Acute post-injury symptoms, such as headache, dizziness, sensitivity to light or noise, double vision or tinnitus, are associated with the development of persistent symptoms (19, 42, 43). A clinical risk score in children has identified headache, sensitivity to noise, fatigue and answering questions slowly as predictive of post-concussion symptoms at 28 days post-injury (44). In addition, the experience of post-concussion symptoms early post-injury ( 1 week -1 month) is consistently associated with higher odds of persistent post-concussion symptoms (10,

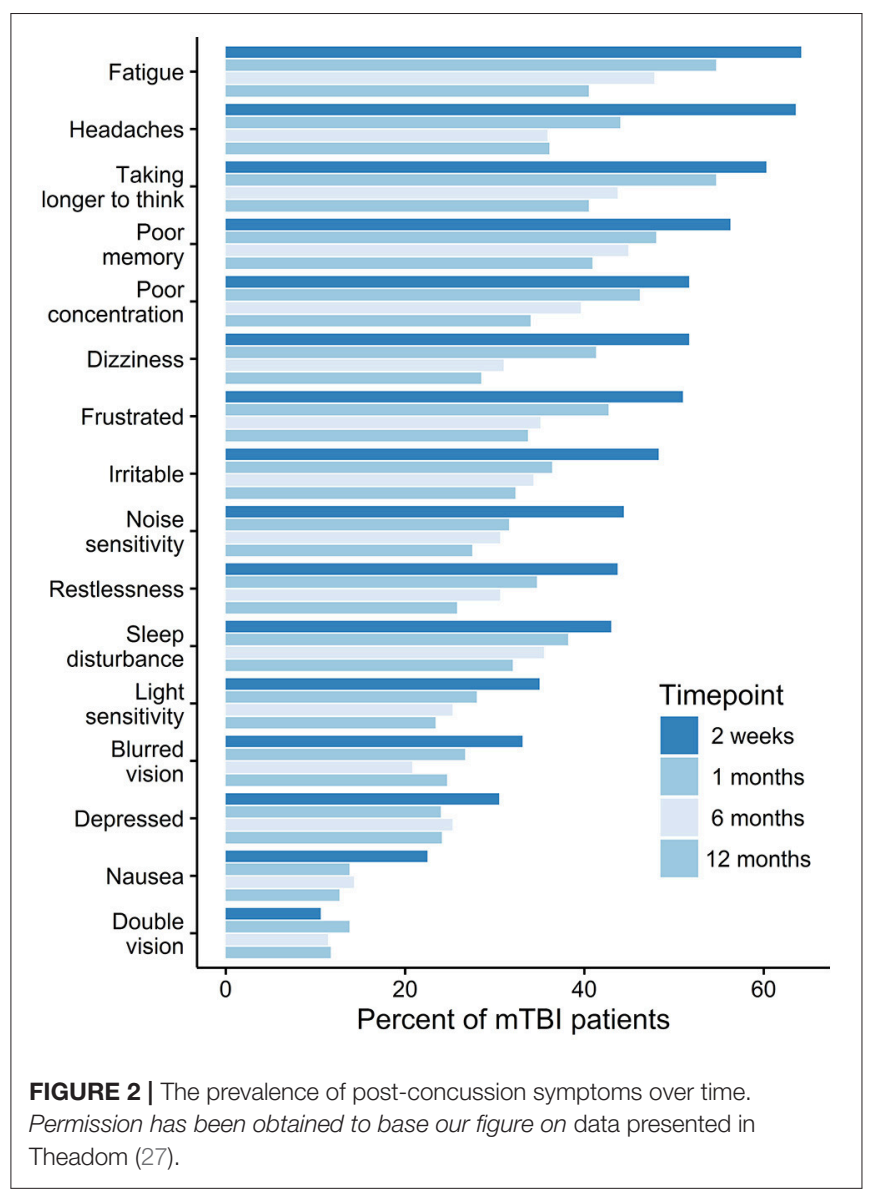

45). A study from 2015 found that $82 \%$ out of 103 patients who were experiencing post-concussion symptoms 1 year after mTBI had already reported these 1 month post injury (46).

\section{Biological Factors and Persistent Post-concussion Symptoms}

Several, predominantly biological factors, such as diffuse axonal injury, neuro-inflammation, and altered cerebral blood flow have been implicated in the genesis of post-concussion symptoms after mTBI $(41,47,48)$. However, these factors have not yet been analyzed in high-quality prognostic studies. The role of biological factors is supported by findings that repetitive $\mathrm{mTBI}$ is associated with increased symptom prevalence (49, 50), longer time to symptom resolution $(50,51)$, and a minimal effect of neurocognitive deficits (52). Similarly, repetitive sub-concussive impacts, e.g., in contact sports, have also been associated with minor long-term neuropsychological sequelae (53), abnormalities in both neuroimaging and in neuropsychological testing (54), and with the development of severe neurodegenerative conditions such as chronic traumatic encephalopathy (CTE) (54). Although many symptoms of CTE overlap with post-concussion symptoms (e.g., irritability, impulsivity, depression, (short-term) memory loss), current evidence on the association of repetitive sub-concussive impacts with CTE is limited and should be considered preliminary (55). 
A major controversy in attempting to identify the role of biological factors in the development of post-concussion symptoms is their weak relationship with injury severity and the high prevalence of PCS-like symptoms in non-brain injured patients, as well as in healthy participants $(10,35,37-40,45,56)$.

Even though most studies report that the rate of postconcussion symptoms is higher among brain-injured patients as compared to non-brain injured trauma controls (32, 46, 57-59), the high rate of false-positives needs to be taken into account when examining biological factors. It should be acknowledged that biological factors do not exist in isolation but need to be interpreted in the context of potentially confounding factors, e.g., pre- and post-injury physical and mental health, trauma, and psychosocial factors $(10,58-60)$.

\section{Psychiatric, Psychological, (Psycho)-Social Factors and Post-concussion Symptoms} Psychiatric Factors

Many post-concussion symptoms (e.g., sleep difficulties, irritability and concentration problems) are similar to symptoms of the hyperarousal dimension of posttraumatic stress disorder (PTSD) (59), which may occur following exposure to severe, often life-threatening events. PTSD following mild, moderate, or severe TBI has a pooled prevalence rate of $13.8 \%(10.2-$ $17.4 \%$ ) (61) and appears to follow TBI more frequently than any other traumatic injuries not involving the brain $(47,62)$. Given the overlap between post-concussion and PTSD symptoms $(59,62,63)$, careful differential diagnosis is required. Nevertheless, a prospective study including 534 brain-injured patients and 827 controls found that mTBI was a significant predictor for PTSD but not for post-concussion symptoms (59). It is not yet clear, whether these results also hold true for pediatric samples. A smaller prospective study comparing parent-reported post-concussion symptoms and PTSD symptoms in 186 children after mTBI and 99 children with non-head orthopedic injuries reported higher rates of post-concussion symptoms after mTBI but comparable rates of PTSD symptoms (63).

Almost half of patients with persistent post-concussion symptoms suffer from premorbid depression and anxiety (47, 64). Pre-injury mental health status has repeatedly been shown to predict persistent post-concussion symptoms in adult (41, $45,47,65)$ and pediatric populations $(13,35)$. However, the question of causality remains unclear, as psychiatric symptoms might be a reaction to experiencing persistent post-concussion symptoms, and/or mental health problems might increase the risk of reporting persisting symptoms.

\section{Psychological Factors}

Recall biases have been shown to influence reports of postconcussion symptoms after mTBI. Patients after mTBI expecting to experience post-concussion symptoms show higher symptom rates than patients not expecting to experience post-concussion symptoms (66). Similarly, in some patients the "good-old-days" bias may lead them to underestimate pre-injury symptoms $(41,57)$. If gross overrepresentation of symptoms is suspected (malingering), performance in selected neuropsychological tests can indicate whether the patient is exerting optimal effort $(11,67)$.

Finally, symptoms commonly occurring in everyday life, such as headache, irritability, sleep disturbance and forgetfulness may be misattributed to brain trauma $(11,33)$. Extensive assessments for putative somatic origins of such common symptoms may further make one believe that these symptoms are indicative of serious brain damage, leading to hypervigilance and catastrophic attributions, comparable to behaviors seen in patients with somatoform disorders or hypochondriasis $(11,33,62,67,68)$.

\section{Socio-Demographic, Social, and Personality Factors}

Female sex is consistently associated with greater reporting of persistent post-concussion symptoms (45). Gender effects appear to be smaller in children $(35,37,56)$. Some studies found that post-concussion symptoms are associated with lower education in adults (45) and pre-injury learning difficulties in children (37). Community integration, social support, lifestyle, and family dynamics may contribute to the development and persistence of post-concussion symptoms in adults $(41,69)$, and children (13, 70). However, conclusive evidence has not yet been established.

The five-factor model of Widiger and colleagues is a model of basic personality traits, consisting of five domains: neuroticism, extraversion, openness, agreeableness, and conscientiousness (71). Basic personality traits as captured in the five-factor model do not appear to be associated with persistent post-concussion symptoms (10). However, more specific traits such as high anxiety sensitivity (72), low resilience (73), coping styles (33, 74) or alexithymia (72) may be associated with persistence of symptoms. However, the cross-sectional design and small sample sizes in these studies hamper the establishment of firm conclusions in the area.

\section{Predicting Persistent Post-concussion Symptoms}

The identification of risk factors might be especially useful for clinical practice when combined into a prognostic model predicting patients at risk of poor outcome. However, current models are often based on small samples $(9,75)$ and lack internal and external validation $(10,45,75,76)$. In addition, no model is able to reliably predict outcomes at the individual patient level (45). Therefore, identification of high-risk patients might best be accomplished by careful and dense follow-up data collection. Advances in study and modeling methodology and, possibly, the incorporation of advanced imaging, and biochemical biomarkers (see Panel 1 for recommendations) may improve the ability to identify at-risk patients in the first week post-injury in the future.

\section{CLINICAL ASSESSMENT OF POST-CONCUSSION SYMPTOMS}

Providing optimal care depends on early and reliable identification of patients at risk of developing persistent post-concussion symptoms $(12,80)$ by a multidisciplinary team. Medical examination should include a history of previous TBIs, head and neck injuries, and a detailed description of the number and extent of acute concussion symptoms, preferably using standardized instruments (see Table 2). Special emphasis 
PANEL 1 | Methodological recommendations for studies on post-concussion symptoms after mTBI.

Well-designed confirmatory studies with the following characteristics have been called for to better understand post-concussion symptoms and its consequences:

\begin{abstract}
Study design: Prospective inception cohort studies with appropriate control group (e.g. non-brain injured patients, general population) and appropriate follow-up period to differentiate persistent deficits and symptoms due to post-concussion symptoms from the effects of pre-injury (neuro)psychiatric disorders and other non-mTBI factors. Longitudinal analyses strategies to monitor evolution of post-concussion symptoms in single patients.

Instruments: use crosswalk analysis to compare incidence rates between studies using different post-concussion symptom assessment procedures. At a minimum, aim to include at least some comparable items, i.e., items whose functioning is comparable between patient samples, and evaluate other items relative to these anchor items. Studies on predictors/prediction models (based on Mushkudiani et al. (77) and Steyerberg (78):

- Sample size: $\mathrm{N}>500$

- Predictors should be based on theory, clinical knowledge or previous research

- For every predictor considered there should be at least ten cases (i.e., patients classified as having PCS)

- A liberal $p$-value (e.g., $p<0.157$ ) (79) should be used when applying selection procedures

- Results should be internally validated (e.g., bootstrap validation)

- Both discrimination and calibration statistics should be mentioned; a score chart is warranted for implementation in clinical practice

- External validation: external validation in an independent dataset is a prerequisite before implementation in clinical practice. External validation and updating

of an existing model should be prioritized against the development of a new model.
\end{abstract}

should also be placed on the assessment of co-morbid injuries and disorders, such as chronic headache, and other pain, cervical-disorders, visual or vestibular disorders, chronic fatigue, sleep, and somatoform disorders $(35,65,80,81)$. However, checklists alone are not sufficient to provide a diagnosis of persistent post-concussion symptoms as a disorder in the absence of a comprehensive multidimensional medical, neurological, and psychiatric and (neuro)psychological evaluation $(64,82)$.

Since persistence of post-concussion symptoms has been associated with pre-, peri-, and post-injury psychological distress and risk of psychiatric disorders (PTSD, depression, anxiety, substance abuse, somatoform disorders), anamnesis should also include an assessment of pre-injury and current mental health difficulties (see Table 2) $(10,28,61,64)$. Finally, information on social and legal factors, such as availability of social support, life stressors, and involvement in legal proceedings needs to be collected (81).

A variety of symptom checklists exist to assess somatic, emotional, and cognitive post-concussion symptomatology, and require patients to indicate presence, absence, frequency, or intensity/severity of symptoms. Neuropsychological performance based outcomes include measures of attention, memory, concentration, orientation and executive function, and can corroborate subjective complaints of impaired cognition. However, cognitive deficits after mTBI are usually transient (28) and appear to be only weakly related to subjective complaints (23). Standard neuropsychological procedures should be followed to ensure that test results are not influenced by comorbid disorders [e.g., attention deficit hyperactivity disorder, and dyslexia $(83,84)]$, or inadequate understanding of test and questionnaire requirements, or low effort (85). Currently, only the field of sport concussion utilizes short reliable and sensitive screening instruments $(7-10 \mathrm{~min})$ to identify possible symptoms (86). A comprehensive overview of instruments suitable for clinical assessment is presented in Table 2. This overview is based on common data elements (CDE) recommendations (87-89) and frequent clinical use.

\section{Neuroimaging and Persistent Post-concussion Symptoms}

No consensus has been reached on the relevance of imaging indicators of brain abnormalities for prognosis and outcome after mTBI. Figure 3 presents magnetic resonance imaging (MRI) images of patients with post-concussion symptoms. Several studies have shown that measures derived from MRI (80, 90-92) or magnetic resonance spectroscopy (MRS) can reveal structural or functional abnormalities in adults and children with an otherwise normal CT (35). Thus, for some patients, persistence of post-concussion symptoms may be explained by yet unknown brain abnormalities. However, current evidence is equivocal and the few large-scale, prognostic studies available suggest only small effects (93), if at all.

\section{Post-concussion Symptoms and Outcome: Health Related Quality of Life, Return to Work, and Societal Costs}

Health outcome can be classified along three dimensions: healthrelated quality of life (HRQoL), functional, and economic outcome. Available studies suggested that post-concussion symptoms correlate with lower levels of life-satisfaction (69, 94) and HRQoL (95). HRQoL measures supplement functional and mental health outcomes with information on how health conditions influence patients' self-reports of their subjective wellbeing. HRQoL represents an important outcome after TBI, as it provides well-standardized information on the recovery patterns and frequency, nature, severity, and duration of the functional consequences (96). Post-concussion symptoms have been linked to lower levels of satisfaction with life (69) and HRQoL in adults (94) and children (97). However, given the association of preinjury physical and mental health status with persistent postconcussion symptoms, the specificity of these findings is still unclear. Further research is needed to isolate the specific effects of persistent symptoms on HRQoL (14).

Furthermore, post-concussion symptoms are associated with reduced return to work $(69,98,99)$. There is a need to focus 
TABLE 2 | Selection of Post-concussion symptoms assessments (adults and children) based on CDE recommendations and frequent clinical use.

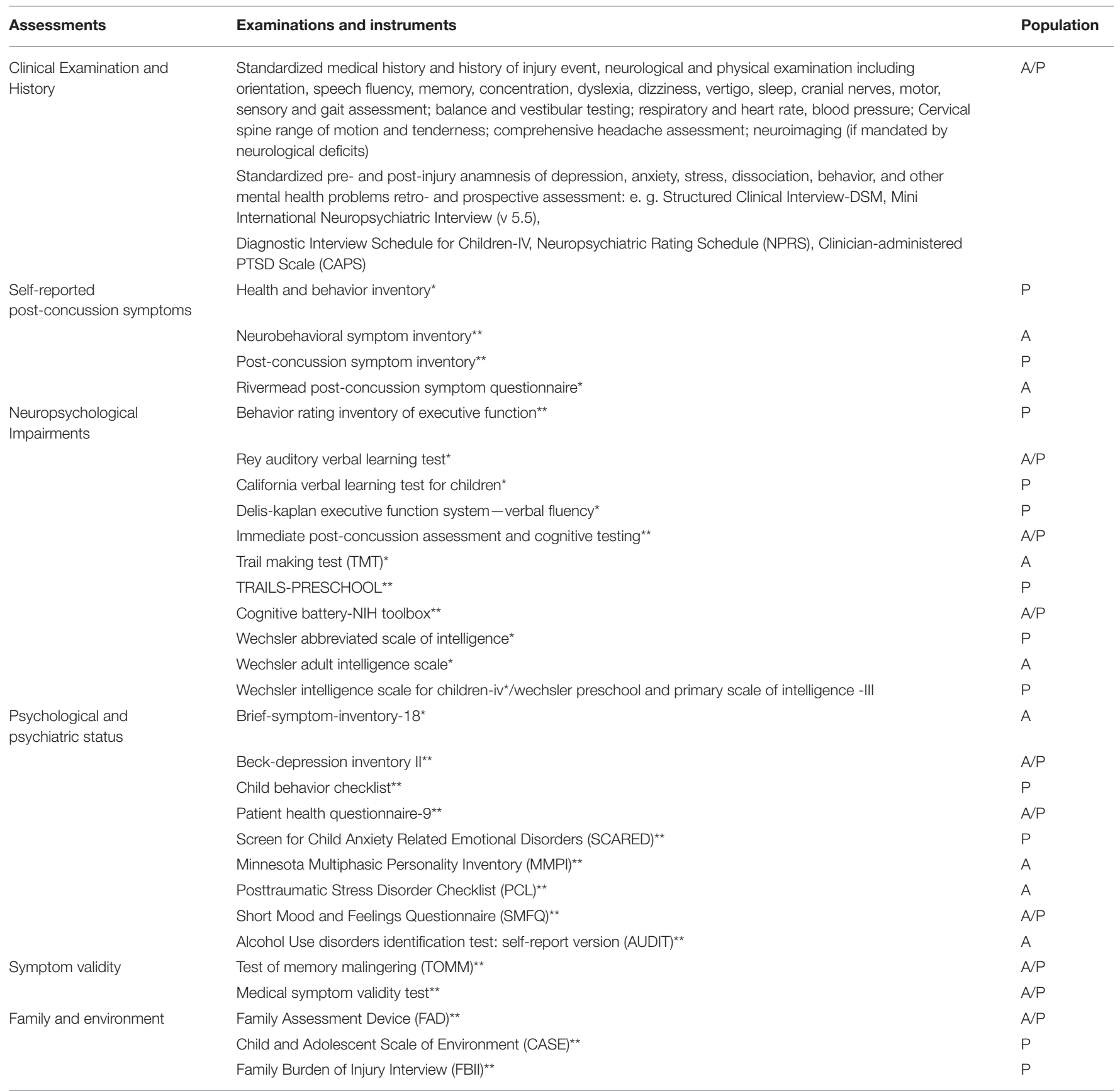

"Common Data Elements (CDES) recommended as basic measure; " CDEs recommended as supplemental measure; A, Adult TBI; P, Pediatric TBI.

on the management of persistent post-concussion symptoms to facilitate return to work (100).

The societal costs of TBI include direct medical costs and indirect expenses related to the illness and the value of lost production due to reduced working time or impaired work performance. A large part of the total lifetime costs in the field of TBI are associated with mTBI. The high incidence of mTBI, combined with a large group of patients with long-term post-concussion symptoms, results in a substantial societal and economic burden (101).

Carefully designed longitudinal research on HRQoL, functional recovery, costs and return to work is needed to differentiate persistent deficits and symptoms due to post-concussion symptoms from the effects of pre-injury neuropsychiatric disorders and other factors not associated with mTBI (14). 

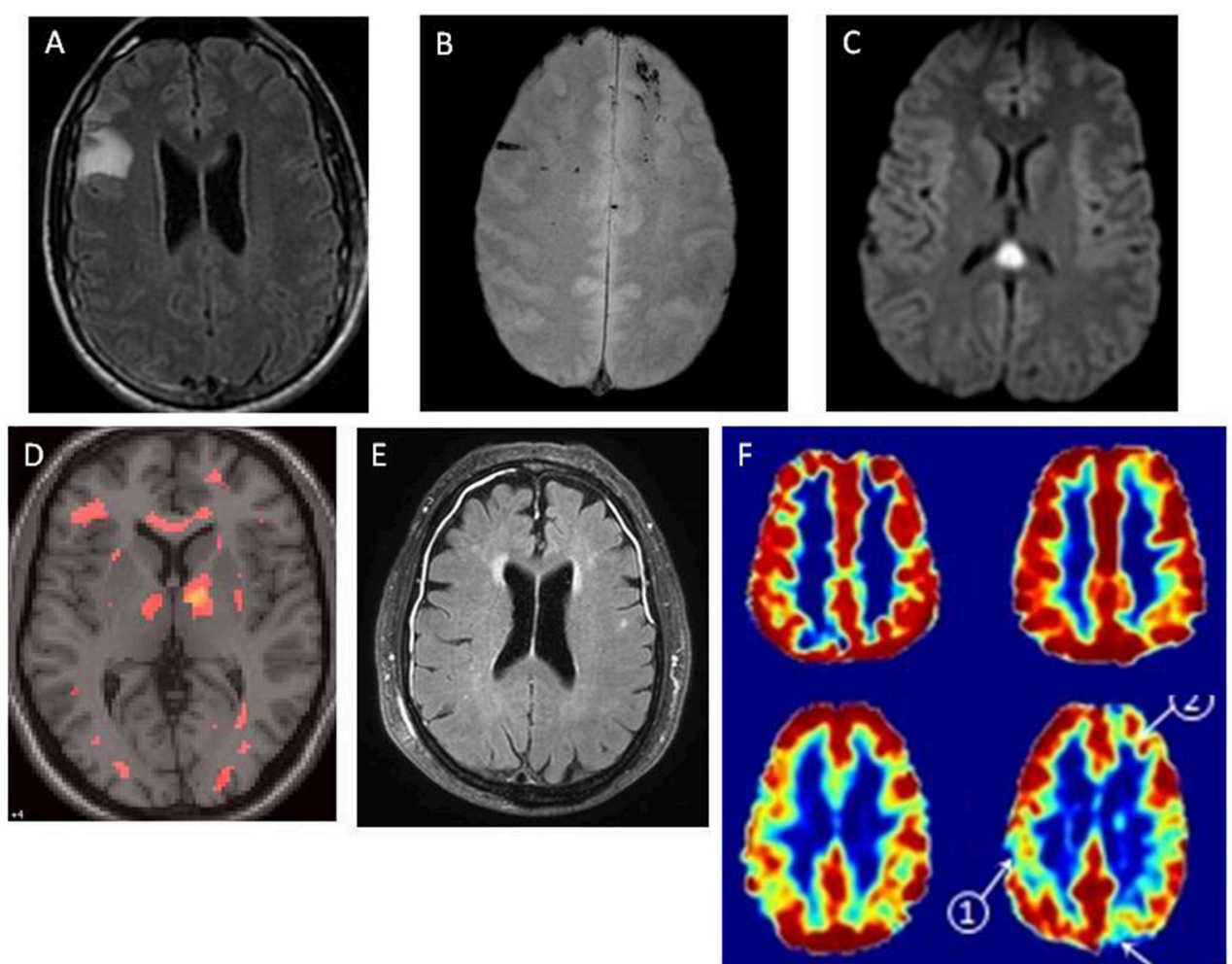

FIGURE 3 | Magnetic resonance images of patients with post-concussion symptoms. MRI findings in patients with mTBI, demonstrating multiple pathologies. In each case, cranial CT was normal. MRI was obtained within $48 \mathrm{~h}$ on injury. (A) Right frontal non-hemorrhagic contusion, noted on FLAIR image. (B) Linear

microhemorrhages in left and right frontal lobes, noted on T2* image. (C) Diffuse axonal injury lesion in splenium of corpus callosum, with restricted diffusion noted on DWI image. (D) Diffuse axonal injury, with multifocal lesions noted on diffusion tensor imaging (DTI). (E) Traumatic meningeal enhancement of subdural effusions, noted on post-gadolinium FLAIR image. (F) Traumatic microvascular injury.

- Top row represents a single healthy control. Bottom row represents a single TBI patient.

- Left column: Cerebral Blood Flow (CBF), assessed by arterial spin labeling.

- Right column: Cerebrovascular reactivity (CVR) assessed using BOLD response to hypercapnia. Credit for figures: Figures A, B, C, E: Larry Latour, PhD, NINDS/NIH; D: Carlos Marquez de la Plata, PhD, University of Texas at Dallas; F: Franck Amyot, PhD, Uniformed Services University of the Health Sciences.

\section{MANAGEMENT OF PATIENTS WITH POST-CONCUSSION SYMPTOMS}

\section{Pharmacological Interventions}

The evidence for pharmacological treatment of depression, anxiety, and mood lability after mTBI is limited and conflicting. A meta-analysis evaluating the effectiveness of depression treatment after mTBI found that studies using a pre-post design suggested treatment benefits from selective serotonin reuptake inhibitors (102). In contrast, the overall effects of controlled trials included in this meta-analysis did not reveal significant differences between treatment and control groups, with some evidence favoring the control condition (102). However, a recently published RCT found sertraline to be effective in preventing depression following TBI when administered early after injury (103). These findings may have considerable therapeutic implications for patients after TBI, but future studies are needed to replicate results before a change in the treatment guidelines could be recommended.

\section{Non-pharmacological Interventions}

Evidence concerning the benefits of non-pharmacological interventions targeting post-concussion symptoms is limited. Early educational interventions in ED patients after mTBI may be promising in reducing the incidence and severity of post-concussion symptoms since a single-center RCT focusing on symptom management delivered via telephone counseling demonstrated reduced chronification of post-concussion symptoms during the first 3 months post-injury (104). This finding could not be replicated in a multi-center study; however the investigated patients showed mixed severity of TBI (105).

A recent study suggests that cognitive behavioral therapy (CBT) can improve HRQoL in patients with persistent postconcussion symptoms in the context of outpatient rehabilitation services (106). However, the effect of CBT on post-concussion symptoms was only marginal (106). Problem orientation and problem-solving skills seem to improve by neuropsychological rehabilitation addressing self-regulation of cognitive and emotional processes (107), but evidence is limited. 
Evidence for beneficial effects of neuropsychological rehabilitation concerning post-concussion symptoms is limited. A systematic review found evidence that, when applied early, such approaches may be efficient in reducing self-reported post-concussion symptoms, anxiety and depression, but do not result in a clear reduction of cognitive impairment (108).

Intervention studies in children and adolescents are highly variable, of limited methodological quality, and evidence to support any particular intervention for post-concussion symptoms in pediatric samples is absent $(109,110)$. In adults, as in pediatric populations, well-designed prospective studies focusing on non-pharmacological multidimensional intervention that show improvement on variables such as HRQoL and return to play and work are still lacking.

\section{Rest and Post-concussion Symptoms}

Historically, "rest" has been a foundation in the treatment of acute $\mathrm{mTBI}$ (70). Concerns have been raised regarding the expertbased consensus recommendation for rest after acute concussion, as studies in adults $(111,112)$ and children (113) indicate that prolonged rest, longer than 3 days to a week may contribute to prolonged symptomatology (114), and no reduction in postconcussion symptoms was found in a study on rest interventions (115).

\section{Vestibular and Vision Rehabilitation Therapy}

The traumatic event resulting in mTBI may also cause concomitant cervical soft tissue damage, resulting in "whiplashrelated" symptoms such as headache, dizziness, and balance dysfunction as well as cognitive, vestibular and visual dysfunction (38). A RCT comparing cervical spine physiotherapy and vestibular rehabilitation therapy (VRT) with a control condition in athletes found that among the intervention group, a significantly higher proportion of individuals were medically cleared after 8 weeks of treatment (116). However, a recent systematic review concluded that current evidence for optimal prescription and efficacy of VRT in patients after mTBI is still limited (117). In addition, large retrospective cohorts including both adults and children examining vision rehabilitation for vision disorders associated with mTBI have demonstrated clinical improvement in conditions such as convergence and accommodative insufficiency (118-120). Thus, high-level studies evaluating the effects and optimal intervention window for VRT and vision rehabilitation are required.

\section{Headaches}

Headaches are among the most disabling symptoms after mTBI. Most post-traumatic headaches show clinical features of a recognized primary headache, such as migraine headaches or tension headaches. Post-traumatic migraines may respond to the same abortive and prophylactic treatments as sporadic migraines (121). In addition, non-pharmacological approaches such as biofeedback, physical therapy, CBT, either as primary or adjunctive treatments, have also been successfully applied to persistent post-concussion headaches $(65,122)$.

\section{CONCLUSIONS AND FUTURE DIRECTIONS}

Despite a sharp increase in studies investigating post-concussion symptoms, controversies and debates still exists with regard to etiology, diagnosis, classification systems, pathophysiology, natural history, prevalence, and terminology. The subjective nature of post-concussion symptoms, their low specificity, and the significant overlap with other physical, neurological, and psychiatric conditions add additional challenges to these discussions $(10,12,19,39,44,45,56,59,82)$. The frequent overlap and idiosyncratic interplay of post-concussion symptoms with pre- and post-injury psychiatric, psychological and social factors are still under-investigated and necessitate a standardized comprehensive differential diagnosis of comorbid mental conditions, in particular depression, anxiety disorders and PTSD.

In this review, we described possible factors contributing to post-concussion symptoms from a bio-psychosocial perspective. Insights into the complex nature of post-concussion symptoms may support the risk estimate of persistent symptoms in individual patients. In addition, it may provide targets for predictive modeling which combine the different factors contributing to post-concussion symptoms. Currently, no valid model is available to predict post-concussion symptoms in adults and children $(45,75)$. Future predictive modeling studies could be improved by using solid methodology (see Panel 1). However, the feasibility of predictive modeling may be debated given the complex, controversial, and multifactorial nature of post-concussion symptoms. Therefore, investing in routine and economic follow-up methods (e.g., smartphone-based experience sampling approaches which have demonstrated feasibility and utility in the post-injury setting $(123,124)$ might be prioritized over predictive models.

The frequent reliance on simple symptom questionnaires for diagnosis ignores possible biases (10) and the fact that the major classification systems require several other criteria to be fulfilled, such as performance-based evidence of cognitive impairment (21). Most questionnaires were developed in and for patients with more severe deficits, thus their sensitivity and specificity in mTBI may be limited. More refined neuropsychological tests, especially those sensitive enough to assess cognition after mTBI, may support the diagnosis of post-concussion symptoms. Moreover, short screening batteries (computerized and paper and pencil) are needed for use in EDs and in general practice. This is aligned with international attempts at developing and implementing standards for clinical research (e.g., CDEs) (87), terminology and diagnosis criteria for post-concussion symptoms.

The heterogeneous nature of mTBI and post-concussion symptoms and the lack of reliable biological predictors and clinically useful gold-standard biomarkers (34) hamper the development of disease-modifying therapies. A first step may be the identification of specific biochemical (125) and imaging biomarkers that can complement clinical diagnosis, inform prognosis by identifying patients at risk for post-concussion symptom persistence, and predict treatment response $(90,101)$. Portable, lower-cost imaging modalities such as functional near 
infrared spectroscopy warrant further investigation to determine their clinical utility in diagnosis and management of mTBI (126).

Large-scale multidimensional, prospective longitudinal studies with several measurement points are strongly required to tackle current challenges in studying post-concussion symptoms. Such designs would allow stratified subgroup analyses to identify patients at risk for developing persistent symptoms, and might help to advance early and personalized treatment. Depending on the research question, improved designs should include control groups to provide insight into the spontaneous recovery, progression, injury severity, frequency, intensity, and fluctuation (trauma controls and healthy participants) of post-concussion symptoms.

Due to normal variation in developmental trajectories, outcomes in children after mTBI may be particularly variable. Longitudinal large sample studies $(>100)$ that investigate predictors of post-concussion symptoms in pediatric populations with multiple endpoints, adequate controls are especially important since high neurologic and cognitive plasticity is present here.

Although evidence for effective treatments is limited, a multidisciplinary approach corresponding to the complex etiology of post-concussion symptoms may be the most promising. Such an approach would combine in-depth comprehensive medical and neurological diagnosis with an emphasis on psychiatric differential diagnostics and psychosocial und neuropsychological outcome assessment. Future treatment directions (repetitive transcranial magnetic stimulation, vestibular and vision rehabilitation therapy, and aerobic exercise) may offer a solution for the basic pathological processes associated with post-concussion symptoms (65).

Standardization of treatment and interventions, outcome measures (87), and follow-up assessment time-points would enhance reliability and validity of research comparisons and individualized treatment. One might speculate as to whether post-concussion symptoms represent the most valid endpoint for treatment/study after mTBI. Given their low specificity, it may well be that other outcomes (e.g., functional outcome and HRQoL) prove to be more useful.

In this focused review, we only included prospective cohort studies with at least 100 participants, and reviews, with some exceptions (Appendix A). Ten included studies did not meet these criteria $(20,29,30,39,40,57,72,83,84,127)$. For these topics, there was no prospective study with at least 100 participants available. Therefore, prospective, multicenter research with larger patient samples is needed. In addition, it should be noted that studies fulfilling our quality criteria might

\section{REFERENCES}

1. Brazinova A, Rehorcikova V, Taylor MS, Buckova V, Majdan M, Psota M, et al. Epidemiology of traumatic brain injury in Europe: a living systematic review. J Neurotrauma (2015). doi: 10.1089/neu.2015.4126. [Epub ahead of print]. still be at risk of bias. Attrition is a recurrent problem $(45,75)$, that may have influenced the reported prevalence rates, the relevance of etiological factors and treatment effectiveness. In addition, some studies of etiological factors were based only on univariable analyses, while multivariable assessment is highly recommended because of the multifactorial nature of postconcussion symptoms.

To summarize, standardization of the multidimensional comprehensive diagnostics, treatment interventions, and followup assessment time-points may enhance reliability and validity of research comparisons and refine personalized treatment and care. This review documents the need for future studies to target the identification of potential mechanisms, new imaging techniques, comprehensive multidisciplinary assessment and treatment options. Longitudinal, well controlled studies applying standardized diagnostic assessment strategies and evidencebased interventions are needed in adult and pediatric mTBI populations to optimize recovery and reduce burden of postconcussion symptoms.

\section{AUTHOR CONTRIBUTIONS}

SP and NvS wrote and revised the manuscript, finalized the paper based on authors, and reviewer feedback. MC conducted the search strategy, screened papers, extracted data of eligible papers, wrote, and revised the manuscript. RD-A, RR, JH, AC, CM, AG, and DV wrote and revised the manuscript. All authors critically reviewed and approved the final version of the paper.

\section{ACKNOWLEDGMENTS}

The paper has been written in the context of the CENTERTBI and TRACK-TBI projects, large scale collaborative projects embedded within the framework of the International initiative on TBI research. CENTER-TBI has received funding from the European Union Seventh Framework Program (FP7/20072013) under grant agreement $n^{\circ}$ 602150. TRACK-TBI has received funding from the National Institutes of Neurologic Disorders and Stroke, grant $\mathrm{n}^{\circ}$ U01 NS086090. We would like to thank Professor Andrew Maas for critically reviewing the manuscript.

\section{SUPPLEMENTARY MATERIAL}

The Supplementary Material for this article can be found online at: https:/www.frontiersin.org/articles/10.3389/fneur. 2018.01113/full\#supplementary-material 
4. American Congress of Rehabilitation Medicine (ACRM). Definition of mild traumatic brain injury. J Head Trauma Rehabil (1993) 8:86-7.

5. World Health Organization. The ICD-10 Classification of Mental and Behavioural Disorders: Diagnostic Criteria for Research. Geneva: WHO (1993).

6. American Psychiatric Association. Diagnostic and Statistical Manual of Mental Disorders, 4th Ed (DSM-IV). Washington, DC: American Psychiatric Association (1994).

7. Hiploylee C, Dufort PA, Davis HS, Wennberg RA, Tartaglia MC, Mikulis D, et al. Longitudinal study of postconcussion syndrome: not everyone recovers. J Neurotrauma (2016) 34:1511-23. doi: 10.1089/neu.2016.4677

8. Ruff RM. Mild traumatic brain injury and neural recovery: rethinking the debate. NeuroRehabilitation (2011) 28:167-80. doi: 10.3233/NRE-2011-0646

9. Caplain S, Blancho S, Marque S, Montreuil M, Aghakhani N. Early detection of poor outcome after mild traumatic brain injury: predictive factors using a multidimensional approach a pilot study. Front Neurol. (2017) 8:666. doi: 10.3389/fneur.2017.00666

10. Cassidy JD, Cancelliere C, Carroll LJ, Côté P, Hincapié CA, Holm LW, et al. Systematic review of self-reported prognosis in adults after mild traumatic brain injury: results of the international collaboration on mild traumatic brain injury prognosis. Arch Phys Med Rehabil. (2014) 95(3 Suppl.):S132-51. doi: 10.1016/j.apmr.2013.08.299

11. Evans RW. Persistent post-traumatic headache, postconcussion syndrome, and whiplash injuries: the evidence for a non-traumatic basis with an historical review. Headache (2010) 50:716-24. doi: 10.1111/j.1526-4610.2010.01645.x

12. Arciniegas DB, Anderson CA, Topkoff J, McAllister TW. Mild traumatic brain injury: a neuropsychiatric approach to diagnosis, evaluation, and treatment. Neuropsychiatr Dis Treat. (2005) 1:311-27.

13. Yeates KO. Mild traumatic brain injury and postconcussive symptoms in children and adolescents. J Int Neuropsychol Soc. (2010) 16:953-60. doi: $10.1017 /$ S1355617710000986

14. Levin HS, Diaz-Arrastia RR. Diagnosis, prognosis, and clinical management of mild traumatic brain injury. Lancet Neurol. (2015) 14:506-17. doi: 10.1016/S1474-4422(15)00002-2

15. Smits M, Hunink MG, van Rijssel DA, Dekker HM, Vos PE, Kool DR, et al. Outcome after complicated minor head injury. AJNR Am J Neuroradiol. (2008) 29:506-13. doi: 10.3174/ajnr.A0852

16. Arbogast KB, Curry AE, Pfeiffer MR, Zonfrillo MR, Haarbauer-Krupa J, Breiding MJ, et al. Point of health care entry for youth with concussion within a large pediatric care network. JAMA Pediatr. (2016) 170:e160294. doi: 10.1001/jamapediatrics.2016.0294

17. Kuppermann N, Holmes JF, Dayan PS, Hoyle JD Jr., Atabaki SM, Holubkov $\mathrm{R}$, et al. Identification of children at very low risk of clinically-important brain injuries after head trauma: a prospective cohort study. Lancet (2009) 374:1160-70. doi: 10.1016/S0140-6736(09)61558-0

18. Babl FE, Borland ML, Phillips N, Kochar A, Dalton S, McCaskill M, et al. Accuracy of PECARN, CATCH, and CHALICE head injury decision rules in children: a prospective cohort study. Lancet (2017) 389:2393-402. doi: 10.1016/S0140-6736(17)30555-X

19. Katz DI, Cohen SI, Alexander MP. Mild Traumatic Brain Injury. Handbook of Clinical Neurology. 127((Katz D.I.) Department of Neurology, Boston University School of Medicine, Boston, MA: Acquired Brain Injury Program, Braintree Rehabilitation Hospital; Braintree, MA: Electronic address: dkatz@bu.edu) (2015) p. 131-56. doi: 10.1016/B978-0-444-52892-6.00009-X

20. Iverson GL, Brooks BL, Ashton VL, Lange RT. Interview versus questionnaire symptom reporting in people with the postconcussion syndrome. J Head Trauma Rehabil. (2010) 25:23-30. doi: 10.1097/HTR.0b013e3181b4b6ab

21. American Psychiatric Association. Diagnostic and Statistical Manual of Mental Disorders, 5th Edn (DSM-5). Washington, DC: American Psychiatric Association (2013).

22. Wortzel HS, Arciniegas DB. The DSM-5 approach to the evaluation of traumatic brain injury and its neuropsychiatric sequelae. NeuroRehabilitation (2014) 34:613-23. doi: 10.3233/NRE-141086

23. Ponsford J, Cameron P, Fitzgerald M, Grant M, Mikocka-Walus A, Schönberger M. Predictors of postconcussive symptoms 3 months after mild traumatic brain injury. Neuropsychology (2012) 26:304-13. doi: $10.1037 / \mathrm{a} 0027888$
24. Iverson GL SN, Lange RT. The Natural History of Mild Traumatic Brain Injury. Manual of Traumatic Brain Injury Assessment and Management. 2nd edn. New York, NY: Demos medical publishing (2016). doi: 10.1891/9781617052699. 0008

25. Boake C, McCauley SR, Levin HS, Pedroza C, Contant CF, Song JX, et al. Diagnostic criteria for postconcussional syndrome after mild to moderate traumatic brain injury. J Neuropsychiatry Clin Neurosci. (2005) 17:350-6. doi: 10.1176/jnp.17.3.350

26. Voormolen DC, Cnossen MC, Polinder S, von Steinbuechel N, Vos PE, Haagsma JA. Divergent classification methods of post-concussion syndrome after mild traumatic brain injury: prevalence rates, risk factors, and functional outcome. J Neurotrauma (2018) 35:1233-41. doi: $10.1089 /$ neu.2017.5257

27. Theadom A, Parag V, Dowell T, McPherson K, Starkey N, Barker-Collo $\mathrm{S}$, et al. Persistent problems 1 year after mild traumatic brain injury: a longitudinal population study in New Zealand. Br J Gen Pract. (2016) 66:e16-23. doi: 10.3399/bjgp16X683161

28. Carroll LJ, Cassidy JD, Cancelliere C, Côté P, Hincapié CA, Kristman $\mathrm{VL}$, et al. Systematic review of the prognosis after mild traumatic brain injury in adults: cognitive, psychiatric, and mortality outcomes: Results of the international collaboration on mild traumatic brain injury prognosis. Arch Phys Med Rehabil. (2014) 95(3 Suppl.):S152-73. doi: 10.1016/j.apmr.2013.08.300

29. Yang CC, Tu YK, Hua MS, Huang SJ. The association between the postconcussion symptoms and clinical outcomes for patients with mild traumatic brain injury. I Trauma (2007) 62:657-63. doi: 10.1097/01.ta.0000203577.68764.b8

30. Dischinger PC, Ryb GE, Kufera JA, Auman KM. Early predictors of postconcussive syndrome in a population of trauma patients with mild traumatic brain injury. J Trauma (2009) 66:289-96. doi: 10.1097/TA.0b013e3181961da2

31. Theadom A, Starkey N, Barker-Collo S, Jones K, Ameratunga S, Feigin $\mathrm{V}$, et al. Population-based cohort study of the impacts of mild traumatic brain injury in adults four years post-injury. PLoS ONE (2018) 13:e0191655. doi: 10.1371/journal.pone.0191655

32. Ponsford J, Cameron P, Fitzgerald M, Grant M, Mikocka-Walus A. Long-term outcomes after uncomplicated mild traumatic brain injury: a comparison with trauma controls. J Neurotrauma (2011) 28:937-46. doi: 10.1089/neu.2010.1516

33. Hou R, Moss-Morris R, Peveler R, Mogg K, Bradley BP, Belli A. When a minor head injury results in enduring symptoms: a prospective investigation of risk factors for postconcussional syndrome after mild traumatic brain injury. J Neurol Neurosurg Psychiatry (2012) 83:217-23. doi: 10.1136/jnnp-2011-300767

34. Mayer AR, Quinn DK, Master CL. The spectrum of mild traumatic brain injury: a review. Neurology (2017) 89:623-32. doi: 10.1212/WNL.0000000000004214

35. Barlow KM. Postconcussion syndrome: a review. J Child Neurol. (2016) 31:57-67. doi: 10.1177/0883073814543305

36. Babcock L, Byczkowski T, Wade SL, Ho M, Mookerjee S, Bazarian JJ. Predicting postconcussion syndrome after mild traumatic brain injury in children and adolescents who present to the emergency department. JAMA Pediatr. (2013) 167:156-61. doi: 10.1001/jamapediatrics. 2013.434

37. Zemek RL, Farion KJ, Sampson M, McGahern C. Prognosticators of persistent symptoms following pediatric concussion: a systematic review. JAMA Pediatr. (2013) 167:259-65. doi: 10.1001/2013.jamapediatrics.216

38. Marshall CM, Vernon H, Leddy JJ, Baldwin BA. The role of the cervical spine in post-concussion syndrome. Phys Sportsmed. (2015) 43:274-84. doi: 10.1080/00913847.2015.1064301

39. Iverson GL, Lange RT. Examination of "postconcussion-like" symptoms in a healthy sample. Appl Neuropsychol. (2003) 10:137-44. doi: 10.1207/S15324826AN1003_02

40. Wang Y, Chan RCK, Deng Y. Examination of postconcussionlike symptoms in healthy university students: relationships to subjective and objective neuropsychological function performance. Arch Clin Neuropsychol. (2006) 21:339-47. doi: 10.1016/j.acn.2006. 03.006 
41. Silverberg ND, Iverson GL. Etiology of the post-concussion syndrome: physiogenesis and psychogenesis revisited. NeuroRehabilitation (2011) 29:317-29. doi: 10.3233/NRE-2011-0708

42. Faux S, Sheedy J, Delaney R, Riopelle R. Emergency department prediction of post-concussive syndrome following mild traumatic brain injury-an international cross-validation study. Brain Inj. (2011) 25:14-22. doi: $10.3109 / 02699052.2010 .531686$

43. Sheedy J, Harvey E, Faux S, Geffen G, Shores EA. Emergency department assessment of mild traumatic brain injury and the prediction of postconcussive symptoms: a 3-month prospective study. J Head Trauma Rehabil. (2009) 24:333-43. doi: 10.1097/HTR.0b013e3181aea51f

44. Zemek R, Barrowman N, Freedman SB, Gravel J, Gagnon I, McGahern C. et al. Clinical risk score for persistent postconcussion symptoms among children with acute concussion in the ED. JAMA (2016) 315:1014-25. doi: 10.1001/jama.2016.1203.

45. Silverberg ND, Gardner AJ, Brubacher JR, Panenka WJ, Li JJ, Iverson GL. Systematic review of multivariable prognostic models for mild traumatic brain injury. J Neurotrauma (2015) 32:517-26. doi: 10.1089/neu.2014.3600

46. Waljas M, Iverson GL, Lange RT, Hakulinen U, Dastidar P, Huhtala H, et al. A prospective biopsychosocial study of the persistent post-concussion symptoms following mild traumatic brain injury. J Neurotrauma (2015) 32:534-47. doi: 10.1089/neu.2014.3339

47. Reuben A, Sampson P, Harris AR, Williams H, Yates P. Postconcussion syndrome (PCS) in the emergency department: Predicting and pre-empting persistent symptoms following a mild traumatic brain injury. Emerg Med J. (2014) 31:72-7. doi: 10.1136/emermed-2012-201667

48. Barlow KM, Marcil LD, Dewey D, Carlson HL, Macmaster FP, Brooks $\mathrm{BL}$, et al. Cerebral perfusion changes in post-concussion syndrome: a prospective controlled cohort study. J Neurotrauma. (2017) 34:996-1004. doi: 10.1089/neu.2016.4634

49. Theadom A, Parmar P, Jones K, Barker-Collo S, Starkey NJ, McPherson $\mathrm{KM}$, et al. Frequency and impact of recurrent traumatic brain injury in a population-based sample. J Neurotrauma (2015) 32:674-81. doi: 10.1089/neu.2014.3579

50. Eisenberg MA, Andrea J, Meehan W, Mannix R. Time interval between concussions and symptom duration. Pediatrics (2013) 132:8-17. doi: 10.1542/peds.2013-0432

51. Benson BW, Meeuwisse WH, Rizos J, Kang J, Burke CJ. A prospective study of concussions among National Hockey League players during regular season games: the NHL-NHLPA Concussion Program. CMAJ. (2011) 183:905-11. doi: 10.1503/cmaj.092190

52. Belanger HG, Spiegel E, Vanderploeg RD. Neuropsychological performance following a history of multiple self-reported concussions: a meta-analysis. $J$ Int Neuropsychol Soc. (2010) 16:262-7. doi: 10.1017/S1355617709991287

53. Manley G, Gardner AJ, Schneider KJ, Guskiewicz KM, Bailes J, Cantu RC, et al. A systematic review of potential long-term effects of sport-related concussion. $\mathrm{Br} J$ Sports Med. (2017) 51:969-77. doi: 10.1136/bjsports-2017-097791

54. Bailes JE, Petraglia AL, Omalu BI, Nauman E, Talavage T. Role of subconcussion in repetitive mild traumatic brain injury. J Neurosurg. (2013) 119:1235-45. doi: 10.3171/2013.7.JNS121822

55. Castellani RJ, Perry G, Iverson GL. Chronic effects of mild neurotrauma: putting the cart before the horse? J Neuropathol Exp Neurol. (2015) 74:493-9. doi: 10.1097/NEN.0000000000000193

56. Taylor HG, Dietrich A, Nuss K, Wright M, Rusin J, Bangert B, et al. Post-concussive symptoms in children with mild traumatic brain injury. Neuropsychology (2010) 24:148-59. doi: 10.1037/a0018112

57. Lange RT, Iverson GL, Rose A. Post-concussion symptom reporting and the "good-old-days" bias following mild traumatic brain injury. Arch Clin Neuropsychol. (2010) 25:442-50. doi: 10.1093/arclin/acq031

58. Dikmen S, Machamer J, Fann JR, Temkin NR. Rates of symptom reporting following traumatic brain injury. J Int Neuropsychol Soc. (2010) 16:401-11. doi: $10.1017 / S 1355617710000196$

59. Lagarde E, Salmi LR, Holm LW, Contrand B, Masson F, Ribereau-Gayon R, et al. Association of symptoms following mild traumatic brain injury with posttraumatic stress disorder vs. postconcussion syndrome. JAMA Psychiatry (2014) 71:1032-40. doi: 10.1001/jamapsychiatry.2014.666
60. Meares S, Shores EA, Taylor AJ, Batchelor J, Bryant RA, Baguley IJ, et al. The prospective course of postconcussion syndrome: the role of mild traumatic brain injury. Neuropsychology (2011) 25:454-65. doi: 10.1037/a00 22580

61. Scholten AC, Haagsma JA, Cnossen MC, Olff M, Van Beeck EF, Polinder S. Prevalence and risk factors of anxiety and depressive disorders following traumatic brain injury: a systematic review. J Neurotrauma (2016) 3:1969-94. doi: 10.1089/neu.2015.4252

62. Bryant R. Post-traumatic stress disorder vs traumatic brain injury. Dialogues Clin Neurosci. (2011) 13:251-62.

63. Hajek CA, Yeates KO, Gerry Taylor H, Bangert B, Dietrich A, Nuss KE, et al. Relationships among post-concussive symptoms and symptoms of PTSD in children following mild traumatic brain injury. Brain Inj. (2010) 24:100-9. doi: 10.3109/02699050903508226

64. Bryant RA, O'Donnell ML, Creamer M, McFarlane AC, Clark CR, Silove D. The psychiatric sequelae of traumatic injury. Am J Psychiatry (2010) 167:312-20. doi: 10.1176/appi.ajp.2009.09050617

65. Hadanny A, Efrati S. Treatment of persistent post-concussion syndrome due to mild traumatic brain injury: current status and future directions. Expert Rev Neurother. (2016) 16:875-87. doi: 10.1080/14737175.2016.1205487

66. Snell DL, Surgenor LJ, Hay-Smith EJC, Williman J, Siegert RJ. The contribution of psychological factors to recovery after mild traumatic brain injury: is cluster analysis a useful approach? Brain Injury (2015) 29:291-9. doi: $10.3109 / 02699052.2014 .976594$

67. Silver JM. Effort, exaggeration and malingering after concussion. J Neurol Neurosurg Psychiatry (2012) 83:836-41. doi: 10.1136/jnnp-2011-302078

68. Ponsford J, Willmott C, Rothwell A, Cameron P, Kelly AM, Nelms R, et al. Factors influencing outcome following mild traumatic brain injury in adults. J Int Neuropsychol Soc. (2000) 6:568-79. doi: 10.1017/S1355617700655066

69. Stalnacke BM. Community integration, social support and life satisfaction in relation to symptoms 3 years after mild traumatic brain injury. Brain Inj. (2007) 21:933-42. doi: 10.1080/02699050701553189

70. Lumba-Brown A, Yeates KO, Sarmiento K, Breiding MJ, Haegerich TM, Gioia GA, et al. Centers for disease control and prevention guideline on the diagnosis and management of mild traumatic brain injury among children. JAMA Pediatr. (2018) 172:e182853. doi: 10.1001/jamapediatrics.2018.2853

71. Widiger TA, Crego C, Rojas SL, Oltmanns JR. Basic personality model. Curr Opin Psychol. (2018) 21:18-22. doi: 10.1016/j.copsyc.2017. 09.007

72. Wood RL, O’Hagan G, Williams C, McCabe M, Chadwick N. Anxiety sensitivity and alexithymia as mediators of postconcussion syndrome following mild traumatic brain injury. J Head Trauma Rehabil. (2014) 29:E9-17. doi: 10.1097/HTR.0b013e31827eabba

73. Sullivan KA, Kempe CB, Edmed SL, Bonanno GA. Resilience and other possible outcomes after mild traumatic brain injury: a systematic review. Neuropsychol Rev. (2016) 26:173-85. doi: 10.1007/s11065-016-9317-1

74. Scheenen ME, Spikman JM, De Koning ME, Van Der Horn HJ, Roks G, Hageman G, et al. Patients "at Risk" of suffering from persistent complaints after mild traumatic brain injury: The role of coping, mood disorders, and post-traumatic stress. J Neurotrauma (2017) 34:31-7. doi: 10.1089/neu.2015.4381

75. Kristman V, Borg J, Godbolt A, Salmi LR, Cancelliere C, Carroll $\mathrm{L}$, et al. Methodological issues and research recommendations for prognosis after mild traumatic brain injury: results of the International Collaboration on MTBI Prognosis (ICoMP). Brain Inj. (2014) 28:817-8. doi: 10.1016/j.apmr.2013.04.026

76. Cnossen MC, Winkler EA, Yue JK, Okonkwo DO, Valadka A, Steyerberg EW, et al. Development of a prediction model for post-concussive symptoms following mild traumatic brain injury: a TRACK-TBI pilot study. $J$ Neurotrauma (2017). doi: 10.1089/neu.2016.4819. [Epub ahead of print].

77. Mushkudiani NA, Hukkelhoven CW, Hernandez AV, Murray GD, Choi SC, Maas AI, et al. A systematic review finds methodological improvements necessary for prognostic models in determining traumatic brain injury outcomes. J Clin Epidemiol. (2008) 61:331-43. doi: 10.1016/j.jclinepi.2007.06.011

78. Steyerberg EW. Clinical Prediction Models. New York,NY: Springer Sciences and Business Media (2009). doi: 10.1007/978-0-387-77244-8 
79. Akaike H. Information theory and an extension of the maximum likelihood principle. In 2nd International Symposium on Information Theory (New York, NY) (1973).

80. McAllister TW, Arciniegas D. Evaluation and treatment of postconcussive symptoms. NeuroRehabilitation (2002) 17:265-83.

81. Ontario Neurotrauma Foundation. Guidelines for Concussion/Mild Traumatic Brain Injury and Persistent Symptoms. Toronto, ON: Ontario Neurotrauma Foundation (2013).

82. Cole W, Bailie, JM. Neurocognitive and Psychiatric Symptoms Following Mild Traumatic Brain Injury. Boca Raton, FL: Translational Research in Traumatic Brain Injury; Taylor \& Francis Group, LLC (2016).

83. McClure DJ, Zuckerman SL, Kutscher SJ, Gregory AJ, Solomon GS. Baseline neurocognitive testing in sports-related concussions: the importance of a prior night's sleep. Am J Sports Med. (2014) 42:472-8. doi: 10.1177/0363546513510389

84. Zuckerman SL, Lee YM, Odom MJ, Solomon GS, Sills AK. Baseline neurocognitive scores in athletes with attention deficit-spectrum disorders and/or learning disability: clinical article. J Neurosurg Pediatr. (2013) 12:1039. doi: 10.3171/2013.5.PEDS12524

85. Heilbronner RL. American Academy of Clinical Neuropsychology (AACN) practice guidelines for neuropsychological assessment and consultation. Clin Neuropsychol. (2007) 21:209-31. doi: 10.1080/13825580601025932

86. Nelson LD, LaRoche AA, Pfaller AY, Lerner EB, Hammeke TA, Randolph C, et al. Prospective, head-to-head study of three Computerized Neurocognitive Assessment Tools (CNTs): reliability and validity for the assessment of sport-related concussion. J Int Neuropsychol Soc. (2016) 22:24-37. doi: 10.1017/S1355617715001101

87. Hicks R, Giacino J, Harrison-Felix C, Manley G, Valadka A, Wilde EA. Progress in developing common data elements for traumatic brain injury research: version two-the end of the beginning. J Neurotrauma (2013) 30:1852-61. doi: 10.1089/neu.2013.2938

88. Thompson HJ, Vavilala MS, Rivara FP. Chapter 1 common data elements and federal interagency traumatic brain injury research informatics system for TBI research. Annu Rev Nurs Res. (2015) 33:1-11. doi: 10.1891/0739-6686.33.1

89. Grinnon ST, Miller K, Marler JR, Lu Y, Stout A, Odenkirchen J, et al. National Institute of Neurological Disorders and Stroke Common Data Element Project - approach and methods. Clin Trials (2012) 9:322-9. doi: $10.1177 / 1740774512438980$

90. Yuh EL, Mukherjee P, Lingsma HF, Yue JK, Ferguson AR, Gordon WA, et al. Magnetic resonance imaging improves 3-month outcome prediction in mild traumatic brain injury. Ann Neurol. (2013) 73:224-35. doi: 10.1002/ana. 23783

91. Shenton ME, Hamoda HM, Schneiderman JS, Bouix S, Pasternak O, Rathi $\mathrm{Y}$, et al. A review of magnetic resonance imaging and diffusion tensor imaging findings in mild traumatic brain injury. Brain Imaging Behav. (2012) 6:137-92. doi: 10.1007/s11682-012-9156-5

92. Khong E, Odenwald N, Hashim E, Cusimano MD. Diffusion tensor imaging findings in post-concussion syndrome patients after mild traumatic brain injury: a systematic review. Front Neurol. (2016) 7:156. doi: 10.3389/fneur.2016.00156

93. Hellstrøm T, Kaufmann T, Andelic N, Soberg HL, Sigurdardottir S, Helseth E, et al. Predicting outcome 12 months after mild traumatic brain injury in patients admitted to a neurosurgery service. Front Neurol. (2017) 8:125. doi: 10.3389/fneur.2017.00125

94. Emanuelson I, Andersson Holmkvist E, Björklund R, Stålhammar D. Quality of life and post-concussion symptoms in adults after mild traumatic brain injury: a population-based study in western Sweden. Acta Neurol Scand. (2003) 108:332-8. doi: 10.1034/j.1600-0404.2003.00155.x

95. King NS, Kirwilliam S. The nature of permanent post-concussion symptoms after mild traumatic brain injury. Brain Impairment (2013) 14:235-42. doi: 10.1017/BrImp.2013.17

96. von Steinbuechel N, Covic A, Polinder S, Kohlmann T, Cepulyte U, Poinstingl $\mathrm{H}$, et al. Assessment of health-related quality of life after TBI: Comparison of a Disease-Specific (QOLIBRI) with a Generic (SF36) instrument. Behav Neurol. (2016) 2016:7928014. doi: 10.1155/2016/79 28014
97. Novak Z, Aglipay M, Barrowman N, Yeates KO, Beauchamp MH, Gravel J, et al. Association of persistent postconcussion symptoms with pediatric quality of life. JAMA, Pediatr. (2016):e162900. doi: 10.1001/jamapediatrics.2016.2900

98. Chu SY, Tsai YH, Xiao SH, Huang SJ, Yang CC. Quality of return to work in patients with mild traumatic brain injury: a prospective investigation of associations among post-concussion symptoms, neuropsychological functions, working status and stability. Brain Inj. (2017) 31:1674-82. doi: 10.1080/02699052.2017.1332783

99. Nolin P, Heroux L. Relations among sociodemographic, neurologic, clinical, and neuropsychologic variables, and vocational status following mild traumatic brain injury: a follow-up study. J Head Trauma Rehabil. (2006) 21:514-26. doi: 10.1097/00001199-200611000-00006

100. Burke MJ, Fralick M, Nejatbakhsh N, Tartaglia MC, Tator CH. In search of evidence-based treatment for concussion: characteristics of current clinical trials. Brain Inj. (2015) 29:300-5. doi: 10.3109/02699052.2014.974673

101. Maas AIR MD, Adelson PD, Andelic N. Traumatic brain injury - integrated approaches to improving clinical care and research. Lancet Neurol. (2017) 16:987-1048. doi: 10.1016/S1474-4422(17)30371-X

102. Barker-Collo S, Starkey N, Theadom A. Treatment for depression following mild traumatic brain injury in adults: a meta-analysis. Brain Inj. (2013) 27:1124-33. doi: 10.3109/02699052.2013.801513

103. Jorge RE, Acion L, Burin DI, Robinson RG. Sertraline for preventing mood disorders following traumatic brain injury: a randomized clinical trial. JAMA Psychiatry (2016) 73:1041-7. doi: 10.1001/jamapsychiatry.2016.2189

104. Bell KR, Hoffman JM, Temkin NR, Powell JM, Fraser RT, Esselman PC, et al. The effect of telephone counselling on reducing post-traumatic symptoms after mild traumatic brain injury: a randomised trial. J Neurol Neurosurg Psychiatry (2008) 79:1275-81. doi: 10.1136/jnnp.2007.141762

105. Bell KR, Brockway JA, Hart T, Whyte J, Sherer M, Fraser RT, et al. Scheduled telephone intervention for traumatic brain injury: A multicenter randomized controlled trial. Arch Phys Med Rehabil. (2011) 92:1552-60. doi: 10.1016/j.apmr.2011.05.018

106. Potter SD, Brown RG, Fleminger S. Randomised, waiting list controlled trial of cognitive-behavioural therapy for persistent postconcussional symptoms after predominantly mild-moderate traumatic brain injury. J Neurol Neurosurg Psychiatry (2016) 87:1075-83. doi: 10.1136/jnnp-2015-312838

107. Cicerone KD, Mott T, Azulay J, Sharlow-Galella MA, Ellmo WJ, Paradise $\mathrm{S}$, et al. A Randomized controlled trial of holistic neuropsychologic rehabilitation after traumatic brain injury. Arch Phys Med Rehabil. (2008) 89:2239-49. doi: 10.1016/j.apmr.2008.06.017

108. Al Sayegh A, Sandford D, Carson AJ. Psychological approaches to treatment of postconcussion syndrome: a systematic review. J Neurol Neurosurg Psychiatry (2010) 81:1128-34. doi: 10.1136/jnnp.2008.170092

109. Winkler R, Taylor NF. Do Children and adolescents with mild traumatic brain injury and persistent symptoms benefit from treatment? A systematic review. J Head Trauma Rehabil. (2015) 30:324-33. doi: 10.1097/HTR.0000000000000114

110. Schneider KJ, Leddy JJ, Guskiewicz KM, Seifert T, McCrea M, Silverberg $\mathrm{ND}$, et al. Rest and treatment/rehabilitation following sport-related concussion: a systematic review. Br J Sports Med. (2017) 51:930-4. doi: 10.1136/bjsports-2016-097475

111. De Kruijk JR, Leffers P, Meerhoff S, Rutten J, Twijnstra A. Effectiveness of bed rest after mild traumatic brain injury: a randomised trial of no versus six days of bed rest. J Neurol Neurosurg Psychiatry (2002) 73:167-72. doi: 10.1136/jnnp.73.2.167

112. Silverberg ND, Iverson GL. Is rest after concussion "the best medicine?": recommendations for activity resumption following concussion in athletes, civilians, and military service members. J Head Trauma Rehabil. (2013) 28:250-9. doi: 10.1097/HTR.0b013e31825ad658

113. Grool AM, Aglipay M, Momoli F, Meehan WP III, Freedman SB, Yeates KO, et al. Association between early participation in physical activity following acute concussion and persistent postconcussive symptoms in children and adolescents. JAMA (2016) 316:2504-14. doi: 10.1001/jama.2016.17396

114. Thomas DG, Apps JN, Hoffmann RG, McCrea M, Hammeke T. Benefits of strict rest after acute concussion: a randomized controlled trial. Pediatrics (2015) 135:213-23. doi: 10.1542/peds.2014-0966 
115. Eliyahu L, Kirkland S, Campbell S, Rowe BH. The effectiveness of early educational interventions in the emergency department to reduce incidence or severity of postconcussion syndrome following a concussion: a systematic review. Acad Emerg Med. (2016) 23:531-42. doi: 10.1111/ acem. 12924

116. Schneider KJ, Meeuwisse WH, Nettel-Aguirre A, Barlow K, Boyd L, Kang J, et al. Cervicovestibular rehabilitation in sport-related concussion: a randomised controlled trial. Br J Sports Med. (2014) 48:1294-8. doi: 10.1136/bjsports-2013-093267

117. Murray DA, Meldrum D, Lennon O. Can vestibular rehabilitation exercises help patients with concussion? A systematic review of efficacy, prescription and progression patterns. Br J Sports Med. (2016) 51:442-51. doi: 10.1136/bjsports-2016-096081

118. Gallaway M, Scheiman M, Mitchell GL. Vision therapy for postconcussion vision disorders. Optom Vis Sci. (2017) 94:68-73. doi: 10.1097/OPX.0000000000000935

119. Storey EP, Master SR, Lockyer JE, Podolak OE, Grady MF, Master CL. Near point of convergence after concussion in children. Optom Vis Sci. (2017) 94:96-100. doi: 10.1097/OPX.0000000000000910

120. Storey EP, Wiebe DJ, D'Alonzo BA, Nixon-Cave K, Jackson-Coty J, Goodman $\mathrm{AM}$, et al. Vestibular rehabilitation is associated with visuovestibular improvement in pediatric concussion. J Neurol Phys Ther. (2018) 42:134-41. doi: 10.1097/NPT.0000000000000228

121. Meehan WP. Medical therapies for concussion. Clin Sports Med. (2011) 30:115-24. doi: 10.1016/j.csm.2010. 08.003

122. Watanabe TK, Bell KR, Walker WC, Schomer K. Systematic review of interventions for post-traumatic headache. Pm R. (2012) 4:129-40. doi: 10.1016/j.pmrj.2011.06.003

123. Wiebe DJ, Nance ML, Houseknecht E, Grady MF, Otto N, Sandsmark DK, et al. Ecologic momentary assessment to accomplish real-time capture of symptom progression and the physical and cognitive activities of patients daily following concussion. JAMA Pediatr. (2016) 170:1108-10. doi: 10.1001/jamapediatrics.2016.1979

124. Wong D, Sinclair K, Seabrook E, McKay A, Ponsford J. Smartphones as assistive technology following traumatic brain injury: a preliminary study of what helps and what hinders. Disabil Rehabil. (2017) 39:2387-94. doi: 10.1080/09638288.2016.1226434

125. Calcagnile O, Anell A, Unden J. The addition of S100B to guidelines for management of mild head injury is potentially cost saving. BMC Neurol. (2016) 16:200. doi: 10.1186/s12883-016-0723-Z

126. Ayaz H, Arbogast K, Mohammed F, Kessler R, Wang L, Storey E, Podolak O, Grady M, Mayer AR, McDonald C and Master CL (2018). fNIRS differentiates cognitive workload between concussed adolescents and healthy controls. Front. Hum. Neurosci. Conference Abstract: 2nd International Neuroergonomics Conference. doi: 10.3389/conf.fnhum.2018.227.00068

127. Leddy JJ, Cox JL, Baker JG, Wack DS, Pendergast DR, Zivadinov $\mathrm{R}$, et al. Exercise treatment for postconcussion syndrome: A pilot study of changes in functional magnetic resonance imaging activation, physiology, and symptoms. J Head Trauma Rehabil. (2013) 28:241-9. doi: 10.1097/HTR.0b013e31826da964

Conflict of Interest Statement: The authors declare that the research was conducted in the absence of any commercial or financial relationships that could be construed as a potential conflict of interest.

Copyright (C) 2018 Polinder, Cnossen, Real, Covic, Gorbunova, Voormolen, Master, Haagsma, Diaz-Arrastia and von Steinbuechel. This is an open-access article distributed under the terms of the Creative Commons Attribution License (CC BY). The use, distribution or reproduction in other forums is permitted, provided the original author(s) and the copyright owner(s) are credited and that the original publication in this journal is cited, in accordance with accepted academic practice. No use, distribution or reproduction is permitted which does not comply with these terms. 